\title{
DFT-evaluasie van bio-geïnspireerde Fe(II)-komplekse vir metaanoksidasie
}

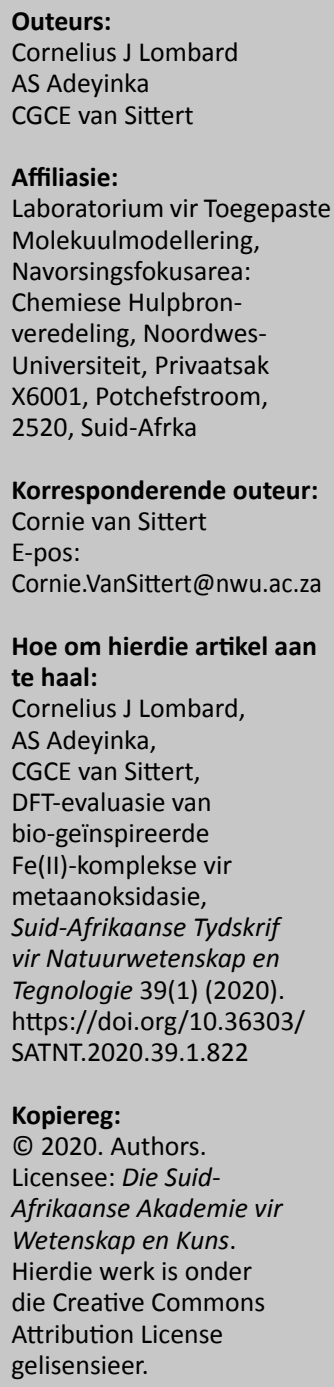

DFT evaluation of bioinspired Fe(II) complexes for methane oxidation: This study evaluated various DFT methods to establish a benchmark for modelling $\left[\mathrm{LFe}^{(\mathrm{II})}\left(\mathrm{CF}_{3} \mathrm{SO}_{3}\right)_{2}\right]_{2}$ complexes. These organometallic complexes serve as precursors for $\left[\mathrm{LFe}^{\mathrm{v}} \mathrm{OOH}\right]^{2+}$ catalysts, employed in methane oxidation. The $\left[\mathrm{LFe}^{\mathrm{v} O O H}\right]^{2+}$ catalysts were constructed from optimised reference structures of $\left[\mathrm{LFe}^{(\mathrm{II})}\left(\mathrm{CF}_{3} \mathrm{SO}_{3}\right)_{2}\right]$ complexes and their ability to abstract hydrogen from methane was investigated.

Petrochemiese brandstowwe bly die oorheersende energiebron van die $21^{\text {ste }}$ eeu. Die benutting van hierdie energiebronne veroorsaak omgewings-, sowel as volhoubaarheidsbekommernisse (Olah, 2005; Ravi et al., 2017). Verbranding van petrochemiese brandstowwe stel skadelike gasse in die atmosfeer vry. Die ontwikkeling van skoon benuttingsprosesse van petrochemiese brandstowwe is dus kardinaal. Die uitputting van steenkool- en oliebronne veroorsaak dat meer aandag op natuurlike gas gerig word (Arutyunov, 2014). Daar word verwag dat die verbruik van natuurlike gas in die volgende twee dekades sal verdubbel (Conti et al., 2016).

Die hoofkomponent van enige natuurlike gas is metaangas. Die grootste struikelblok in die omskakeling van metaangas na metanol is die uitsonderlike hoë bindingsenergie van kovalente $\mathrm{C}$-H-bindings. Die aktivering van ' $\mathrm{C}$ C-H-binding benodig ongeveer $435 \mathrm{~kJ} \cdot \mathrm{mol}^{-1}$ energie (Postils et al., 2015). Hierdie hoë energievereiste maak grootskaalse omskakeling onprakties.

Daar bestaan egter natuurlike prosesse waar C-H-aktivering moeiteloos geskied. ' $n$ Voorbeeld hiervan is die ensiematiese katalise van metaan deur mono-oksigenase met sitochroom P-450 in metaboliese prosesse (Canta et al., 2014). Nabootsing van hierdie proses vereis nabootsing van die aktiewe biokatalisators (byvoorbeeld triflaatkomplekse soos $\left[\mathrm{LFe}^{\mathrm{II}}\left(\mathrm{CF}_{3} \mathrm{SO}_{3}\right)_{2}\right]$ wat in die ensiem voorkom, waar $\mathrm{L}=\mathrm{N}, \mathrm{N}$-dimetiel-N,N-bis(2-piridielmetiel)-sikloheksaan-1,2diammien, N,N-dimetiel-N,N-bis-(2-piridielmetiel)-etaan-1,2-diammien, (\{(S)-2-[(S)-1-(piridin2-ielmetiel)pirrolidin-2-iel] pirrolidin-1-iel)\}metiel)piridien of 1-(2-piridielmetiel)-4,7-dimetiel1,4,7-triazasiklono-naan (PyTACN).

Hierdie triflaatkomplekse kan met behulp van die digtheidsfunksionaalteorie (DFT) ondersoek word. Tans is daar egter geen DFT-berekeningsmaatstaf beskikbaar vir die beskrywing van triflaatkomplekse nie (Canta et al., 2014).

In hierdie studie is ' $\mathrm{n}$ maatstaf, wat in die ondersoek van die voorloper Fe(II)-triflaatstrukture $\left[\mathrm{LFe}^{\mathrm{II}}\left(\mathrm{CF}_{3} \mathrm{SO}_{3}\right)_{2}\right]$ gebruik is, vir DFT-berekeninge geïdentifiseer. Die sintese en meganisme van die $\left[\mathrm{LFe}^{\mathrm{V}} \mathrm{OOH}\right]^{2+}$-katalisators is met die geïdentifiseerde DFT-berekeningsmetode ondersoek en hul effektiwiteit in die verlaging van aktiveringsenergie, met betrekking tot die oksidasie van $\mathrm{C}$-H bindings in die $\mathrm{CH}_{4}$-molekuul, is ondersoek.

Hierdie studie het die uw97XD-funksionaal met 6-311+G*-basisstel as die DFT-maatstaf vir die modulering van $\left[\mathrm{LFe}^{\Pi}\left(\mathrm{CF}_{3} \mathrm{SO}_{3}\right)_{2}\right]$-strukture geïdentifiseer. $\left[\mathrm{PyTACNFe}\left(\mathrm{CF}_{3} \mathrm{SO}_{3}\right)_{2}\right]$ is as die optimale voorloperkompleks geïdentifiseer.

\section{Verwysings}

Arutyunov V. 2014. Direct methane to methanol: Foundations and prospects of the process. Elsevier, Amsterdam.

Canta M, Font D, Gomez L, Ribas X, Costas M. 2014. The iron (II) complex [Fe (CF3SO3) 2 (mcp)] as a convenient, readily available catalyst for the selective oxidation of methylenic sites in alkanes. Advanced Synthesis \& Catalysis $356(4), 818-830$.

Conti J, Holtberg P, Diefenderfer J, et al. 2016. International energy outlook 2016 with projections to 2040. USDOE Energy Information Administration (EIA), Washington.

Olah GA. 2005. Beyond oil and gas: the methanol economy. Angewandte Chemie International Edition 44(18), 2636-2639.Postils V, Company A, Solà M, Costas M, Luis JM. 2015. Computational Insight into the Mechanism of Alkane Hydroxylation by Non-heme Fe (PyTACN) Iron Complexes. Effects of the Substrate and Solvent. Inorganic Cemistry 54(17), 8223-8236.

Ravi M, Ranocchiari M, Van Bokhoven JA. 2017. The direct catalytic oxidation of methane to methanol-A critical assessment. Angewandte Chemie International Edition 56(52), 16464-16483.

Nota: 'n Seleksie van referaatopsommings: Studentesimposium in die Natuurwetenskappe, 31 Oktober - 1 November 2019 , Universiteit van die Vrystaat. Reëlingskomitee: Prof Rudi Pretorius (Departement Geografie, Universiteit van Suid-Afrika); Dr Hertzog Bisset (Suid-Afrikaanse Kernenergie-korporasie; Dr Ernie Langner (Departement Chemie, Universiteit van die Vrystaat) en Dr Wynand Nel (Departement Rekenaarwetenskap en Informatika, Universiteit van die Vrystaat). 